\title{
Experiment Research on the Maximum Temperature Difference during Concrete Hydration of Box Girder Bridge Construction
}

\author{
YAO Yue ${ }^{1}$, LEI Xiao ${ }^{1, a}$ and GUO Zhigang ${ }^{2}$ \\ ${ }^{1}$ College of Civil and Transportation Engineering, Hohai University, Nanjing, China \\ ${ }^{2}$ School of Railway Transportation, Shanghai Institute of Technology, Shanghai, China \\ aleix2010@126.com,
}

Keywords: box girder bridge; temperature difference; concrete hydration heat, temperature test

\begin{abstract}
The temperature data of a post-tensioned continuous concrete box-girder bridge have been monitored during concrete hydration period. Based on the measured data, the temperature in the different positions of the concrete box girder section was systemically analyzed to extract the max temperature difference. An experiment method for predicting the extremum temperature of concrete box-girder was proposed. The results show that a larger temperature difference between inside and outside concrete occurred in the course of hardening of concrete, the maximum temperature can reach 62.6 C. Therefore, some certain method to keep concrete surface in a warm mode is necessary. The results are useful in estimating the temperature difference in concrete box-girder construction.
\end{abstract}

\section{Introduction}

Bridge structures are normally subjected to environmental temperature actions ${ }^{[1-3]}$ (solar radiation intensity, ambient air temperature, wind speed, etc.). In the case of concrete bridge, the influence of the climatic conditions, the location and thermal properties of the materials on the magnitude and the profile of temperature and temperature stress distributions have been investigated by several authors ${ }^{[4-6]}$. But during the construction period ,the temperature difference may higher that the service period as the concrete hydration. The temperature of Concrete block which has a large amount of concrete square caused by hydration heat is 30C higher than the environment temperature, especially the members whose thickness is more than $1 \mathrm{~m}^{[7,8]}$.

The main objective of this paper is to report on the monitoring of the temperatures in a continuous, 3 span, prestressed concrete box girder bridge in Jiangsu, China during the construction. The temperature data is used to explore the influence of concrete hydration on the bridge's performance.

\section{Description of the bridge and the monitoring system}

\section{Target Bridge}

The bridge is 280 meter in length and it consists of 3 continuous spans. The outline and scale of the bridge is shown in Fig. 1.The bridge spans are in the south north direction in the eastern part of China.

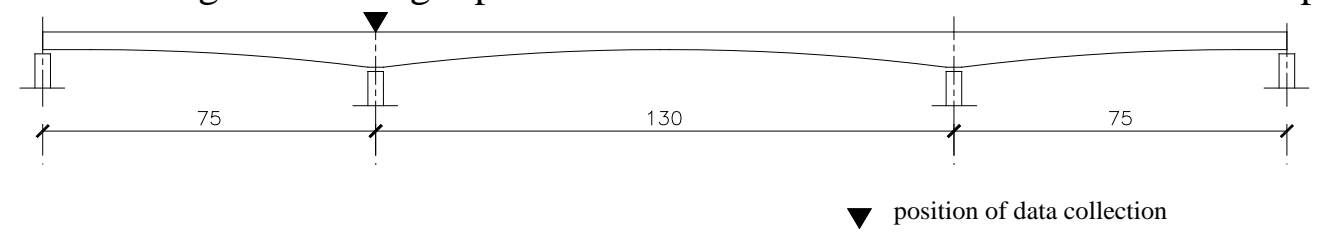

\section{Observation method}

Fig.1. Scale diagram of Bridge(m) and temperature measurement positions

6 temperature sensors (Figure 2) were buried in the transverse direction of bridge in order to calibrate the influence of the temperature changes in the process of construction. The specific location is shown in Figure3, on the top of concrete block just above the bridge pier. 

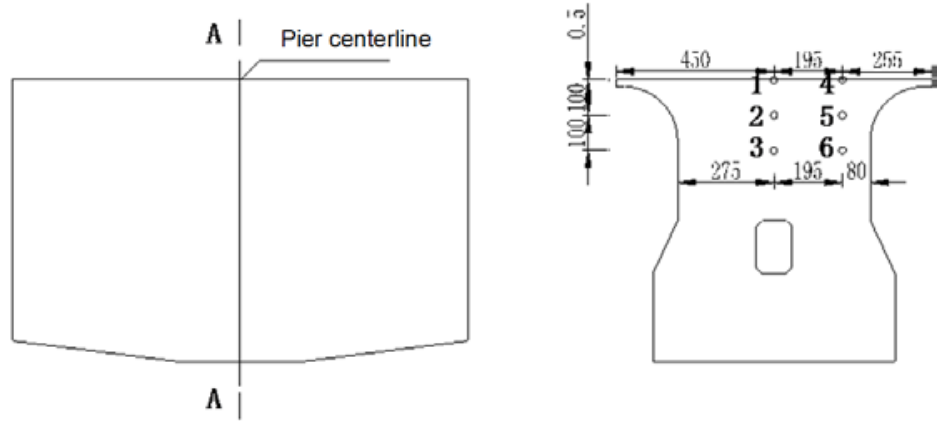

Fig.2 Temperature measuring points (unit: cm)

In the Fig.2, sensor point 1 and sensor point 4 was located on the surface of structure, while sensor point 2 point 6 were located inside the concrete. The temperature had been measured since the concrete pouring began (Fig 3). The frequency was from 1 hour at the beginning of the measurement to 3 hours after measuring the maximum temperature.

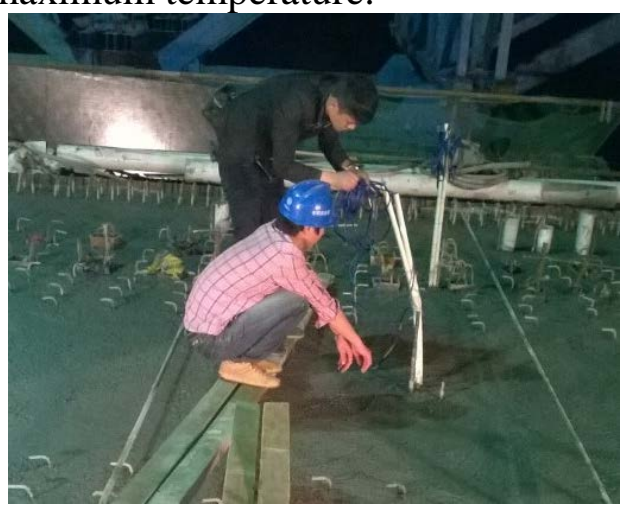

Fig.3 Temperature field testing

\section{Observation Results and Discussion}

Temperature measurements results are shown in Fig.4.

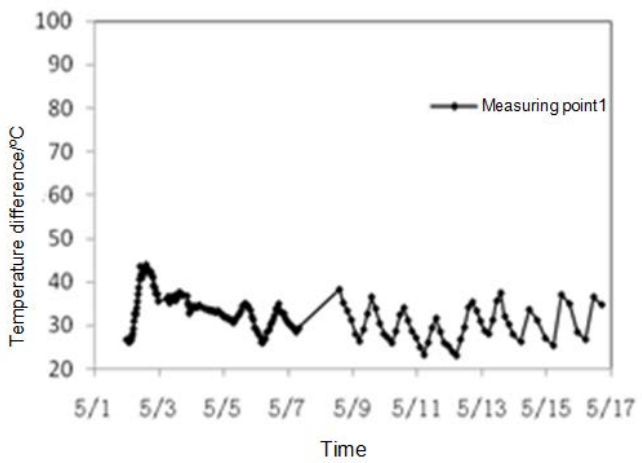

a) Measuring point 1

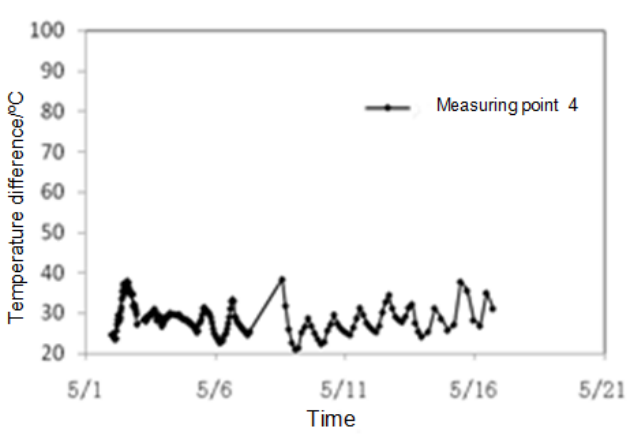

d) Measuring point 4 


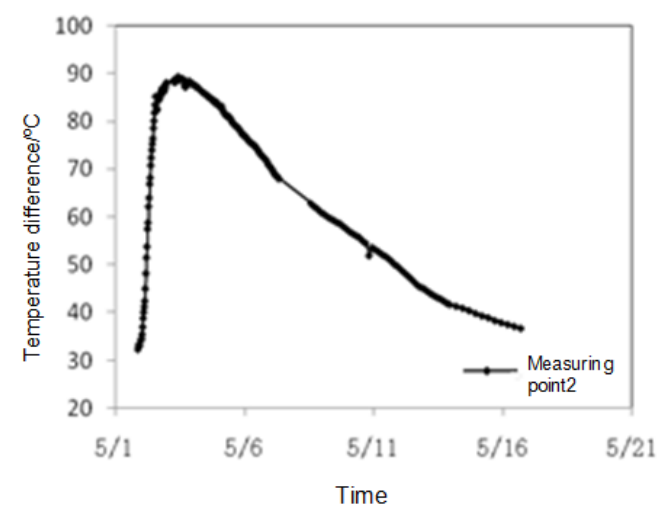

b) Measuring point 2

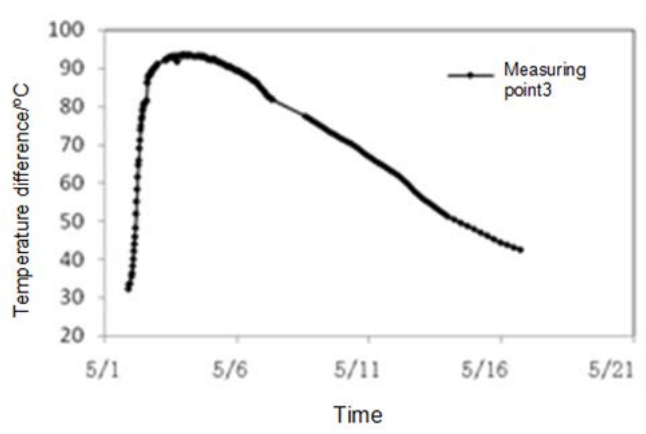

c) Measuring point 3

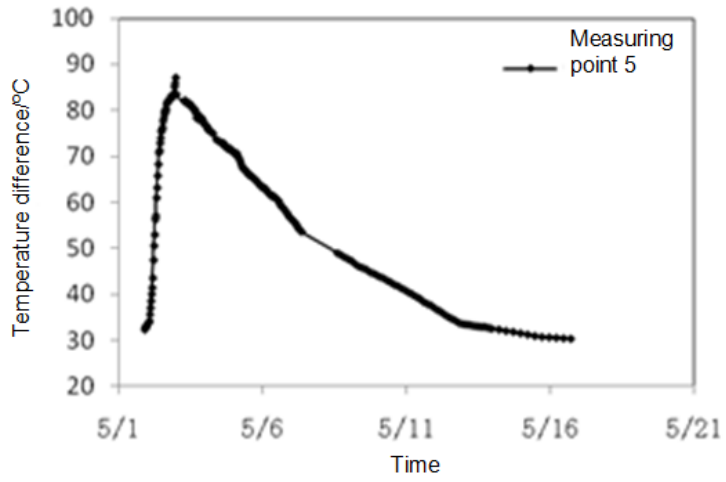

e) Measuring point 5

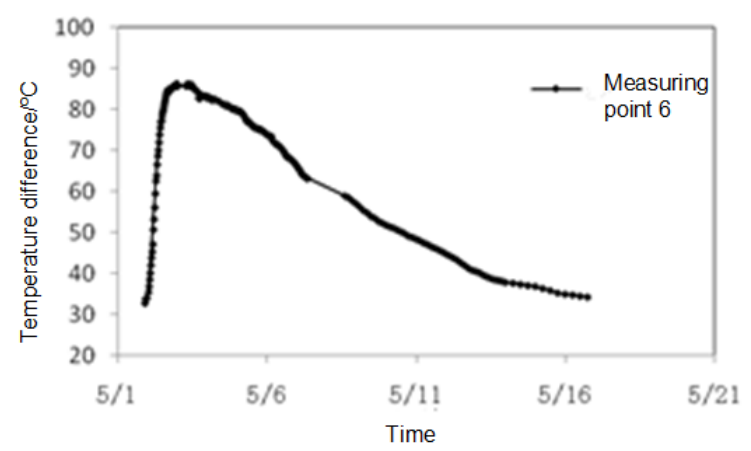

f) Measuring point 6

Fig.4 Each measuring point temperature change map

As Fig 4 shown, the measuring temperature inside the concrete is higher than outside. The maximum temperature occurred in sensor point 3 , about $93.5 \mathrm{C}$. while the temperature of surface points decreased rapidly after heating due to heat dissipation. Therefore, the temperature difference between inside and outside caused by concrete hydration heat cannot be ignored.

Temperature difference results are shown in Fig.5.

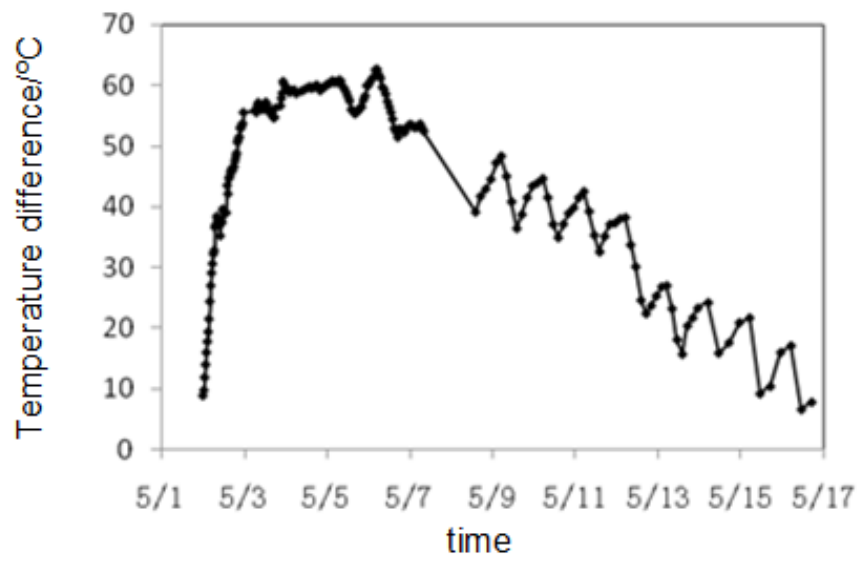

Fig. 5 The temperature difference between point 1 and point 3

As shown in Fig 5, a larger temperature difference between inside and outside occurs in the precipitation process of concrete, the maximum of which can reach $62.6 \mathrm{C}$. Therefore, certain measures were recommended to adopt to keep concrete box gird warm during construction. What's 
more, it can be seen from Fig 5, the decreasing of temperature inside the concrete is a slow process, so the insulation measures should be continued for a long time, at least 20 days.

\section{Summary}

The method based on experiment analysis using temperature sensor can estimate thermal action value of concrete bridge construction successful. a larger temperature difference between inside and outside concrete box girder occurs in the precipitation process of concrete, the maximum of which can reach 62.6 C. Therefore, certain measures were recommended to adopt to keep concrete box gird warm during construction.

\section{Acknowledgements}

This work was financially supported by the National Natural Science Foundation (51108152) and Project of Traffic Science and Technology Program of Zhejiang Province (2014H27)

\section{References}

[1] Ye Jianshu, Jia Lin, Qian Peishu, Observation and research on temperature distribution in concrete box girders. Journal of Southeast University: Natural Science Edition, Vol 32(5), 2002, pp.788-793.(in Chinese)

[2] Lei Xiao, Ye Jianshu, Wang Yi, Representative value of solar thermal difference effect on PC box-girder. Journal of Southeast University : Natural Science Edition, Vol 38(6), 2008, pp.1105-1109.(in Chinese)

[3] Lei Xiao, Ye Jianshu, Wang Yi, et al, Analysis of concrete box-girder temperature and strain based on long term observation. Journal of Jiangsu University: Natural Science Edition, Vol 31(2), 2010, pp.230-234.(in Chinese)

[4] C. L. Roberts-Wollman, J. E. Breen, J. Cawrse, "Measurements of thermal gradients and their effects on segmental concrete bridge”, Journal of Bridge Engineering,Vol 7(3), 2002, pp.166-174.

[5] J. Suzuki, Y. Ohba, Y. Uchikawa, et al. "Monitoring temperatures on a real box-girder bridge and energy budget analysis for basic information on bridge cooling and surface freezing”, Journal of Bridge Engineering, Vol 12(1), 2007, pp.45-52.

[6] J. M. Lucas, M. Virlogeux, C. Louis, “Temperature in the box girder of the normandy bridge”, Structural Engineering International, Vol 15(3), 2005, pp. 156-165.

[7] P. Mondal, J. T. Dewolf, "Development of computer-based system for the temperature monitoring of a post-tensioned segmental concrete box-girder bridge”, Computer-Aided Civil and Infrastructure Engineering, Vol 22(1), 2007, pp. 65-77.

[8] A. Norris, M. Saafi, P. Romine, "Temperature and moisture monitoring in concrete structures using embedded nanotechnology/ microelectromechanical systems(MEMS) sensors”, Construction and Building Materials, Vol 22(2), 2008, pp. 111-120. 